\title{
Paediatric Varicocele and Sports
}

\author{
Giorgio Bolla*, Gianluca Sartore \\ Department of Paediatric Urology - O.C. Dolo (Venice, Italy) \\ *giorgio.bolla@libero.it
}

\begin{abstract}
:
Background: Does it exist a physiological correlation between the appearance of left idiopathic varicocele and the continuous practice of sports? Varicocele is a physical abnormality found in the $11 \%$ of adult males and in the $25 \%$ of those with abnormal semen analysis; this condition is an anatomic and functional anomaly which reveals itself in predisposed boys and in different times.
\end{abstract}

Methods: 117 boys suffering from left idiopathic varicocele - second and third degree - were treated by specific therapy.

Results: 83 boys of the whole treated group carried on the sports continuously - 71\% -, while a clear minority 34 boys (29\%) - didn't effect any sporting activity.

Conclusion: The sports can signify an increase of the oxidative cellular stress, with possible anomalies of the spermatogenesis and an appearance of vascular dilation. The oxidative stress could interfere in the spermatogenesis and the vascular dilation. These are the most pressing questions for the actual clinical studies: the experience of the Authors seems to confirm this hypothesis.

Keywords: Paediatric disease - Varicocele - Oxidative stress

\section{INTRODUCTION}

Varicocele is a physical abnormality found in the $11 \%$ of adult males ${ }^{1}$ and in the $25 \%$ of those with abnormal semen analysis ${ }^{2}$. Varicocele is a meshwork of distended blood vessels in the scrotum usually on the left-side - due to dilatation of the spermatic vein. Although the concept that varicocele causes male subfertility has been around for more than 50 years, the mechanism by which varicocele would affect fertility is not yet clear. Therefore there isn't any sufficient evidence to explain the mechanisms by which varicocelectomy would restore fertility. Furthermore, it has been questioned whether it exists a cause at all between the distension of the pampiniform plexus (a network of many small veins found in the human male spermatic cord) and impairment of fertility. The therapeutic approach for adolescent varicocele remains that of the patient to undergo several treatments, to be compared according to safety and effectiveness ${ }^{3}$.

\section{BACKGROUND}

Varicocele is an anatomic and functional anomaly which reveals itself in predisposed boys and in different times. The Authors valued if there were some conditions able to make easier the appearance of paediatric varicocele; the main correlative interest was about sports 45 .

\section{Materials AND Methods}

117 boys suffering from left idiopathic varicocele - second and third degree - were treated by specific therapy: 62 with high ligature of spermatic vessels and 55 with antegrade sclerotherapy (Fig. 1). The range of age in the treated boys was 11-14 years old (13 boys-11 years old; 18 boys-12 years old; 34 boys-13 years old; 52 boys-14 years old). We obtained the informed consent by the parents and the ethics approval according to Helsinki Declaration. 


\section{TREATMENTS}

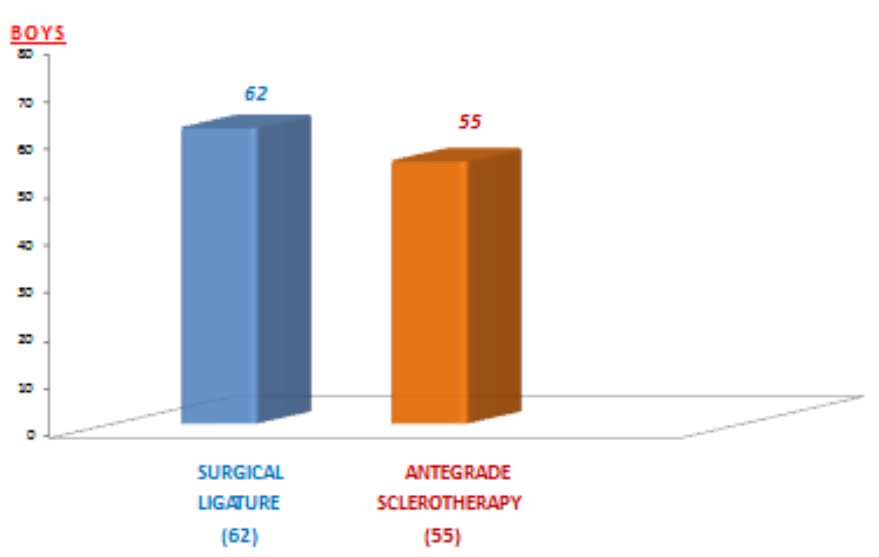

Figure1. Different treatments for the left varicocele

\section{Results}

83 boys of the whole treated group carried on the sports continuously - 71\% - , while a clear minority - 34 boys (29\%) - didn't effect any sporting activity (Fig. 2). Different sporting activities were represented, mostly the football and the cycling. A continuative sporting activity represents the engagement for three days/week and eleven months/year, at least.

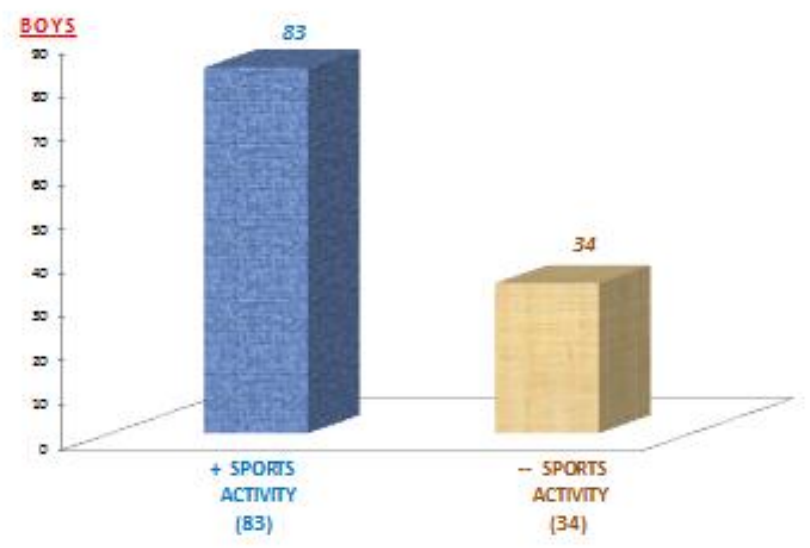

Figure2. Frequency of sporting activity in the treated boys

\section{DISCUSSION}

There is a clear variability on treatment of paediatric varicocele, still now ${ }^{6}$. This aspect indicates an uncertainty about the therapeutical approaches to the problem. The variability regards both the surgical treatments (like the ligature of the vessels or the veins on a different level and like the various vascular anastomoses) and the others therapies (antegrade or retrograde sclerotherapy, retrograde embolisation) ${ }^{7}$. In our opinion the treatment of paediatric varicocele ought to be done at the first diagnosis, in order to prevent a possible future infertility ${ }^{8}$ thus allowing the regular testicular growth ${ }^{9}$. Unavoidably for adolescents the functional fertility evaluation is not possible, for ethical reasons and physical ones (hormone release).

The sports can signify an increase of the oxidative cellular stress, with possible anomalies of the spermatogenesis and an appearance of vascular dilation ${ }^{10}$.

\section{Conclusion}

It is reasonable to hypothesize, by our data (the low number of our sample not yet determines statistical settlements), a more frequent early manifestation of the idiopathic varicocele for the boys who carry on the sports continuously: the comparative frequency of the boys suffering from varicocele is higher than the general national frequency of the sporting adolescent 


\section{REFERENCES}

[1] Hargreave TB. Varicocele. Male infertility. Berlin: Springer-Verlag 1994 .

[2] Nieschlag E, Hertle L, Fischedick A. Treatment of varicocele: counselling as effective as occlusion of the vena spermatica . Hum Reprod, 1995; 10(2):347-353.

[3] Riccabona M, Oswald J, Koen M. Optimizing the operative treatment of boys with varicocele: sequential comparison of 4 techniques. J Urol, 2003; 169(2):666-668.

[4] Bolla G. Why open surgery for treatment of paediatric varicocele? Med Surg Ped, 2014;36:159160 .

[5] Rigano E, Santoro G, Impellizzeri P, et al. Varicocele and sport in the adolescent age. Preliminary report on the effects of physical training. J Endocrinol Invest, 2004; 27(2):130-132.

[6] Kogan SJ. The Pediatric Varicocele . Philadelphia: Saunders, Eds Pediatric Urology, 2001; 763 773.

[7] Feber KM, Kass EJ. Varicocelectomy in adolescent boys: long-term experience with the Palomo procedure. J Urol, 2008;180(4 Suppl.): 1657-1659 .

[8] Laven JS, Haans LC, Mali WP. Effects of varicocele treatment in adolescents: a randomized study. Fertil Steril 1992; 58(4):756-762.

[9] Pinto KJ, Kroovand RL, Jarow JP. Varicocele related testicular atrophy and its predictive effect upon fertility. J Urol 1994; 152:788-790.

[10] Maiorino M, Ursini F. Oxidative stress, spermatogenesis and fertility. Biol Chem, 2002; 383(34):591-597. 